\title{
Twenty-year comparison of tissue and mechanical valve replacement
}

\author{
Steven S. Khan, MD, FACC \\ Alfredo Trento, $\mathrm{MD}^{\mathrm{b}}$ \\ Michele DeRobertis, $\mathrm{RN}^{\mathrm{b}}$ \\ Robert M. Kass, MD ${ }^{b}$ \\ Meenu Sandhu, MSc \\ Lawrence S. C. Czer, MD \\ Carlos Blanche, $\mathrm{MD}^{\mathrm{b}}$ \\ Sharo Raissi, $\mathrm{MD}^{\mathrm{b}}$ \\ Gregory P. Fontana, $M D^{b}$ \\ Wen Cheng, MD \\ Aurelio Chaux, $\mathrm{MD}^{\mathrm{C}}$ \\ Jack M. Matloff, MD*
}

\begin{abstract}
From the Divisions of Cardiothoracic Surgery, ${ }^{\mathrm{b}}$ Cardiology, ${ }^{\mathrm{a}}$ and Biostatistics, ${ }^{\mathrm{c}}$ Departments of Surgery ${ }^{\mathrm{b}}$ and Medicine, ${ }^{\mathrm{a}}$ The Cedars-Sinai Medical Center Burns \& Allen Research Institute, University of California at Los Angeles School of Medicine, Los Angeles, Calif, and the Division of Cardiothoracic Surgery, St John's Hospital, ${ }^{\text {c }}$ Santa Monica, Calif.
\end{abstract}

Read at the Twenty-fifth Annual Meeting of The Western Thoracic Surgical Association, Olympic Valley (Lake Tahoe), Calif, June 23-26, 1999

Received for publication June 29, 1999; revisions requested Sept 8, 1999; revisions received Jan 22, 2001; accepted for publication Feb 19, 2001

Address for reprints: Steven S. Khan, MD, Division of Cardiothoracic Surgery, CedarsSinai School of Medicine, 8700 Beverly Blvd, Room 6215, Los Angeles, CA 90048 (E-mail: khan@cshs.org).

*Chariman, Global Healthcare Alliance; Chairman Emeritus, Cardiothoracic Surgery, Cedars-Sinai Medical Center.

J Thorac Cardiovasc Surg 2001;122:257-69

Copyright (C) 2001 by The American Association for Thoracic Surgery

$0022-5223 / 2001 \$ 35.00+0 \quad \mathbf{1 2 / 6 / 1 1 5 2 3 8}$

doi:10.1067/mtc.2001.115238
Objective: We sought to compare outcomes with tissue and St Jude Medical mechanical valves over a 20 -year period.

Methods: Valve-related events and overall survival were analyzed in 2533 patients 18 years of age or older undergoing initial aortic, mitral, or combined aortic and mitral (double) valve replacement with a tissue valve (Hancock, Carpentier-Edwards porcine, or Carpentier-Edwards pericardial) or a St Jude Medical mechanical valve. Total follow-up was 13,390 patient-years. There were 666 St Jude Medical aortic valve replacements, 723 tissue aortic valve replacements, 513 St Jude Medical mitral valve replacements, 402 tissue mitral valve replacements, 161 St Jude Medical double valve replacements, and 68 tissue double valve replacements. The mean age was $68 \pm 13.3$ years (St Jude Medical valve, $64.5 \pm 12.9$; tissue valve, $72.0 \pm 12.6$ ).

Results: There were no overall differences in survival between tissue and mechanical valves. Multivariable analysis indicated that the type of valve did not affect survival. Analysis by age less than 65 years or 65 years or older and presence or absence of coronary disease revealed similar long-term survival in all subgroups. The risk of hemorrhage was lower in patients receiving tissue aortic valve replacements but was not significantly different in patients receiving mitral valve or double valve replacements. Thromboembolism rates were similar for tissue and mechanical valve recipients. However, reoperation rates were significantly higher in patients receiving both aortic and mitral tissue valves. The reoperation hazard increased progressively with time both in patients receiving aortic and in those receiving mitral tissue valves. Overall valve complications were initially higher with mechanical aortic valves but not with mechanical mitral valves. However, valve complication rates later crossed over, with higher rates in tissue valve recipients after 7 years in patients undergoing mitral valve replacement and 10 years in those undergoing aortic valve replacement.

Conclusions: Tissue and mechanical valve recipients have similar survival over 20 years of follow-up. The primary tradeoff is an increased risk of hemorrhage in patients receiving mechanical aortic valve replacements and an increased risk of late reoperation in all patients receiving tissue valve replacements. The risk of tissue valve reoperation increases progressively with time. 


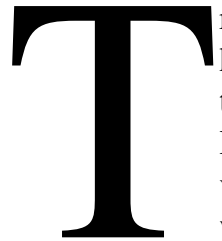
reatment options in patients with valvular heart disease have expanded significantly in the past decade to include procedures like the Ross procedure, homograft aortic and mitral valves, stentless tissue valves, and more widespread use of mitral valve repair. Despite these newer procedures, valve replacement with a prosthetic mechanical valve or with porcine or pericardial xenograft valves remains the standard procedure for most patients with significant valvular heart disease. Although several randomized studies have examined differences in outcomes between patients with tissue and mechanical valves, ${ }^{1,2}$ in clinical practice valve selection is not random. Instead, the selection of a type of prosthetic valve is made primarily on the basis of patient age, ${ }^{3}$ valve position, patient comorbidity, and the risks and benefits of anticoagulation. Significant insights into the performance of tissue and mechanical prosthetic valves in real-life settings can be gained by analysis of a large series of patients receiving these valves. Therefore, the primary purpose of this article is to provide long-term outcome data on the results of prosthetic heart valve replacement, stratifying by valve position (aortic vs mitral) and type of valve received (tissue vs $\mathrm{St}$ Jude Medical mechanical valve replacement), over a 20year period.

\section{Methods}

Data on patients undergoing valve replacement at Cedars-Sinai Medical Center, a private, university-affiliated, tertiary-care medical center, have been prospectively entered into a computerized database since 1969. Patients are mailed annual questionnaires, and those reporting possible events are contacted by a research nurse. If a questionnaire is not returned, a protocol of repeat mailings followed by telephone calls to the patient or his or her physician is followed. The National Death Index is queried for patients whose status cannot be determined. The percentage of patients classified as lost to follow-up was $2.6 \%$ (66/2533). However, another $3.6 \%(92 / 2533)$ of patients are in the midst of the followup protocol, and some of these may eventually be classified as lost to follow-up. The recommendations of The American Association for Thoracic Surgery and Society of Thoracic Surgeons for reporting valve-related morbidity and mortality ${ }^{4}$ were used as guidelines to analyze patient outcomes. However, operative mortality in this study was defined to include all deaths occurring during the hospitalization for the operation or within 30 days of the operation. Deaths within 30 days of reoperation on an operated valve were included as valve-related deaths and as valve complications.

\section{Patient Selection}

Patients over the age of 18 years who had either a porcine or pericardial tissue valve or St Jude Medical bileaflet mechanical valve (St Jude Medical, Inc, St Paul, Minn) implanted in the mitral or aortic positions were included in this study. The analysis was restricted to patients operated on during or after 1976. Tissue valve recipients received either a standard (models 242 [aortic] or 342 [mitral]) or modified-orifice aortic (model $250 \mathrm{H})$ Hancock porcine valve (Medtronic, Inc, Minneapolis, Minn) or a CarpentierEdwards porcine (model 2625 [aortic] or model 6625 [mitral]) or Carpentier-Edwards bovine pericardial aortic valve (model 2700) (Edwards Lifesciences Corporation, Irvine, Calif). Patients were excluded if they received homografts or a combination of both porcine and mechanical valves or if they had any prior valve replacement.

\section{Postoperative Management}

Patients with mechanical valves were started on a regimen of warfarin after the operations. Before 1987, warfarin was adjusted to maintain the prothrombin time (PT) ratio (patient PT/control PT) at 1.5 to 2.5 times the control value. From 1987 to 1992 , the PT ratio was maintained at 1.5 to 2.0 times the control value. Since 1992, warfarin has been titrated to a target international normalized ratio of 2.5 to 3.5. Patients with mitral tissue valves routinely received warfarin for 3 months after the operation. Before 1992, the dose was adjusted to 1.3 to 1.5 times the control value and subsequently adjusted to an international normalized ratio of 2.0 to 3.0. Warfarin therapy in patients with aortic tissue valves was optional and determined by factors such as patient age and risk factors for bleeding or thromboembolism. Tissue valve recipients received long-term aspirin (325 mg orally each day) postoperatively once warfarin was discontinued. Management of anticoagulation after hospital discharge was performed by the patient's own physician but generally followed these guidelines.

\section{Statistical Methods}

Comparisons between continuous variables were made by means of $t$ tests or analysis of variance as appropriate. Comparisons between categorical variables were made by the Fisher exact test or the $\chi^{2}$ test. All baseline factors that differed between tissue and mechanical valve groups were used to test whether valve type was predictive of overall survival after adjusting for baseline differences in risk factors. A stepwise Cox proportional hazards regression analysis was used to select a set of covariates predictive of survival by using a $P$-to-enter value of .10. The final covariate model was then compared with the same model plus valve type. Valve type was considered predictive of survival if the likelihood ratio test was significant at the .05 level. Survival was estimated by using actuarial life-table methods. Survival curve plots in Figures 1 to 3, 5, and 6 are stopped when the population is less than 8 patients. Because of the small number of double valve recipients, the survival analysis and Cox multivariable analyses were only performed in the patients receiving aortic and mitral valve replacements. However, linearized event rates are presented for the patients receiving double valve replacements.

In addition to standard Kaplan-Meier life-table analysis, reoperation rates were also analyzed by the actual or cumulative incidence method. ${ }^{5}$ This technique provides an answer to the following question: What proportion of the patients will require reoperation before they die? We have described our procedure for calculating actual reoperation rates previously. ${ }^{6}$ 


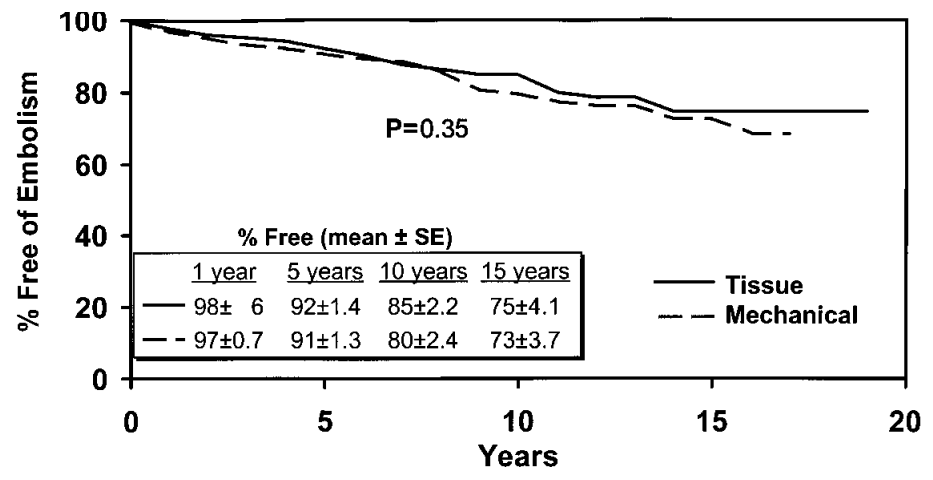

A

Number at Interval

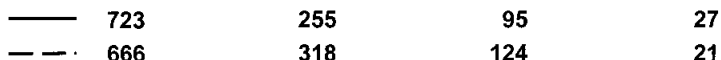

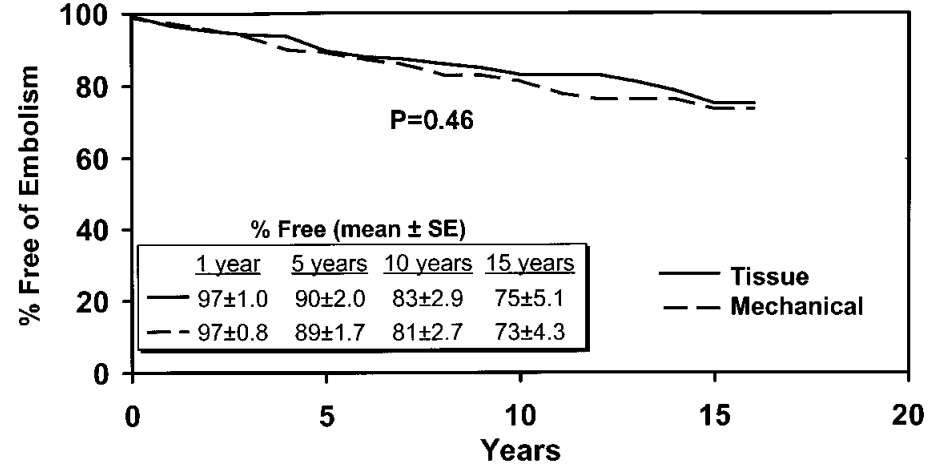

B

Number at Interval

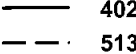

165

70

18

210

80

23

Figure 1. Freedom from embolism for tissue and St Jude Medical valves. A, Aortic valve embolism data; B, mitral valve embolism data. The $P$ value compares tissue and mechanical valve embolism rates. The numbers below the figure are the numbers of patients at risk at the beginning of each time period. NS, Not significant.

TABLE 1. Preoperative patient characteristics

\begin{tabular}{|c|c|c|c|c|}
\hline & Mechanical & Tissue & All & $P$ value \\
\hline No. & 1340 & 1193 & 2533 & \\
\hline Age (y) & $64.5 \pm 12.9$ & $72.0 \pm 12.6$ & $68.0 \pm 13.3$ & .0001 \\
\hline Female sex $(\%)$ & 49.0 & 39.8 & 44.7 & $<.001$ \\
\hline NYHA class IV (\%) & $\begin{array}{c}37.8 \\
(n=1108)\end{array}$ & $\begin{array}{c}40.9 \\
(n=995)\end{array}$ & $\begin{array}{c}39.3 \\
(n=2103)\end{array}$ & .15 \\
\hline Coronary artery disease (\%) & 50.2 & 61.6 & 55.6 & .001 \\
\hline Diabetes (\%) & 14.1 & 14.6 & 14.3 & .78 \\
\hline Prior MI (\%) & 19.3 & 20.0 & 19.7 & .82 \\
\hline Ejection fraction (\%) & $\begin{array}{c}54.0 \pm 14.7 \\
(n=573)\end{array}$ & $\begin{array}{c}53.0 \pm 15.2 \\
(n=636)\end{array}$ & $\begin{array}{c}53.5 \pm 15.0 \\
(n=1209)\end{array}$ & .21 \\
\hline Operative mortality (\%) & 7.9 & 9.8 & 8.8 & .09 \\
\hline CABG $(\%)$ & 44.1 & 55.8 & 49.6 & .001 \\
\hline
\end{tabular}

Values are given as means \pm SD where shown. NYHA, New York Heart Association; CABG, coronary artery bypass grafting; MI, myocardial infarction, NS, not significant $(P>.2)$. 


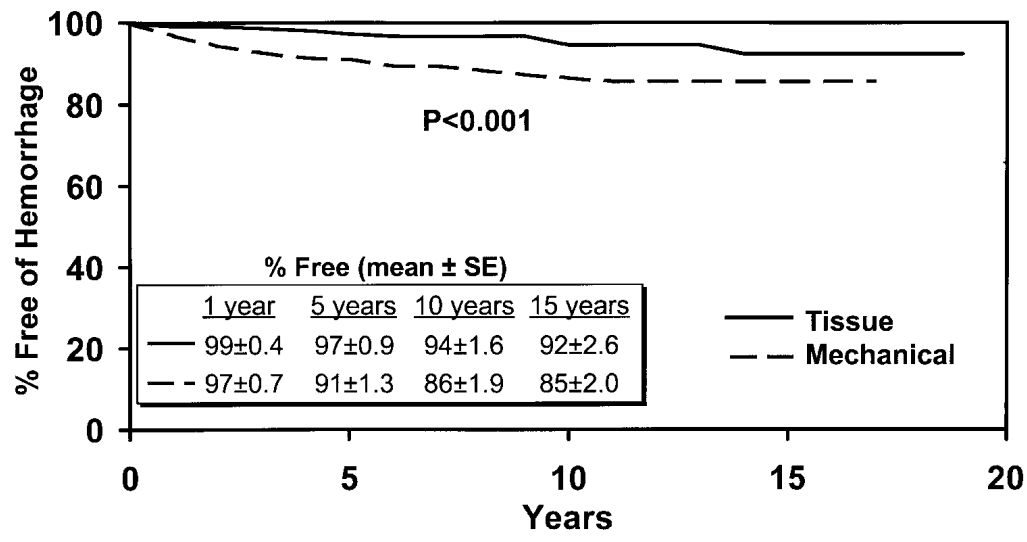

A Number at Interval

$\begin{array}{rrrr}723 & 271 & 103 & 30 \\ --\cdot 666 & 315 & 114 & 21\end{array}$

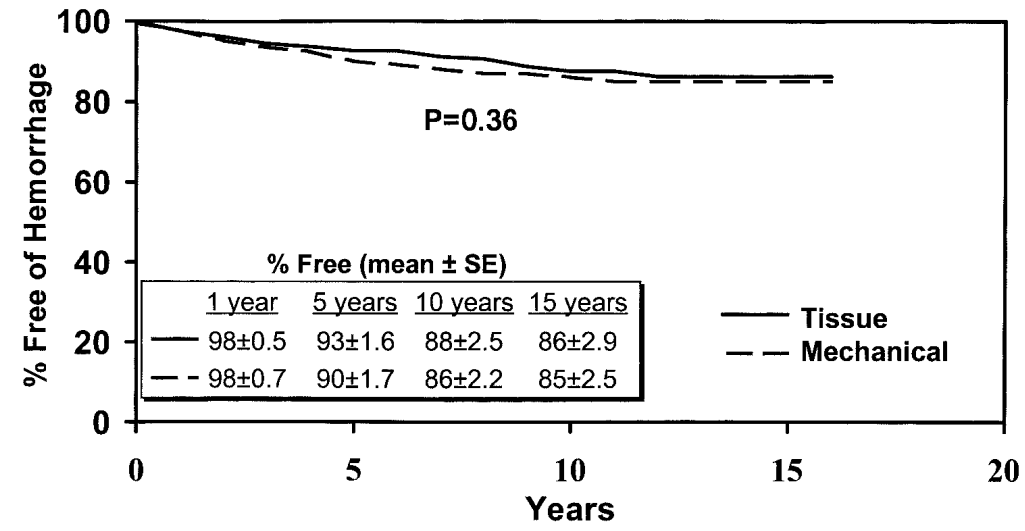

Number at Interval

B $\quad$\begin{tabular}{rrrrr}
- & 402 & 166 & 77 & 20 \\
\hline- & 513 & 211 & 84 & 23
\end{tabular}

Figure 2. Freedom from hemorrhage comparing tissue and St Jude Medical valves stratified by valve position. A, Aortic hemorrhage rates; $B$, mitral hemorrhage rates. NS, Not significant.

TABLE 2. Linearized event rates

\begin{tabular}{|c|c|c|c|c|c|c|}
\hline & \multicolumn{2}{|c|}{ Aortic } & \multicolumn{2}{|c|}{ Mitral } & \multicolumn{2}{|c|}{ Double } \\
\hline & Mechanical & Tissue & Mechanical & Tissue & Mechanical & Tissue \\
\hline No. & 666 & 723 & 513 & 402 & 161 & 68 \\
\hline Patient-years & 3881 & 3387 & 2662 & 2205 & 920 & 336 \\
\hline Endocarditis & $0.3 \%(0.17-0.56)$ & $0.6 \%(0.32-0.86)$ & $0.3 \%(0.14-0.62)$ & $0.5 \%(0.26-0.92)$ & $0.4 \%(0.14-1.19)$ & $2.4 \%(1.11-4.81)$ \\
\hline Hemorrhage & $2.0 \%(1.6-2.5)$ & $0.7 \%(0.44-1.0)$ & $1.9 \%(1.4-2.5)$ & $1.5 \%(1.0-2.1)$ & $3.2 \%(2.1-4.4)$ & $2.1 \%(0.9-4.4)$ \\
\hline Valve thrombosis & $0.3 \%(0.13-0.49)$ & $0.0 \%(0.0-0.14)$ & $0.2 \%(0.05-0.41)$ & $0.05 \%(0.002-0.29)$ & $0.2 \%(0.04-0.87)$ & $0.0 \%(0.03-1.4)$ \\
\hline Embolism & $2.5 \%(2.1-3.1)$ & $2.1 \%(2.7-3.7)$ & $2.9 \%(2.3-3.6)$ & $2.5 \%(1.9-3.3)$ & $3.5 \%(2.4-4.9)$ & $2.1 \%(0.9-4.4)$ \\
\hline Thrombosis + embolism & $2.8 \%(2.3-3.4)$ & $2.1 \%(1.7-2.7)$ & $3.0 \%(2.4-3.7)$ & $2.5 \%(1.9-3.3)$ & $3.7 \%(2.6-5.2)$ & $2.1 \%(0.9-4.4)$ \\
\hline All valve complications & $5.2 \%(4.5-5.9)$ & $4.8 \%(4.1-5.6)$ & $5.6 \%(4.8-6.6)$ & $7.4 \%(6.3-8.5)$ & $7.8 \%(6.2-9.8)$ & $8.6 \%(5.9-12.3)$ \\
\hline
\end{tabular}

Linearized event rates are obtained by dividing the number of events by the total number of patient-years of follow-up. Percentages represent events per 100 patient-years of follow-up or the percentage of events per patient-year. Numbers in parentheses are $95 \%$ confidence intervals. All valve complications includes endocarditis, structural failure, reoperation, hemorrhage, thrombosis, embolism, pannus formation, perivalvular leak, hemolysis, and erosion. 


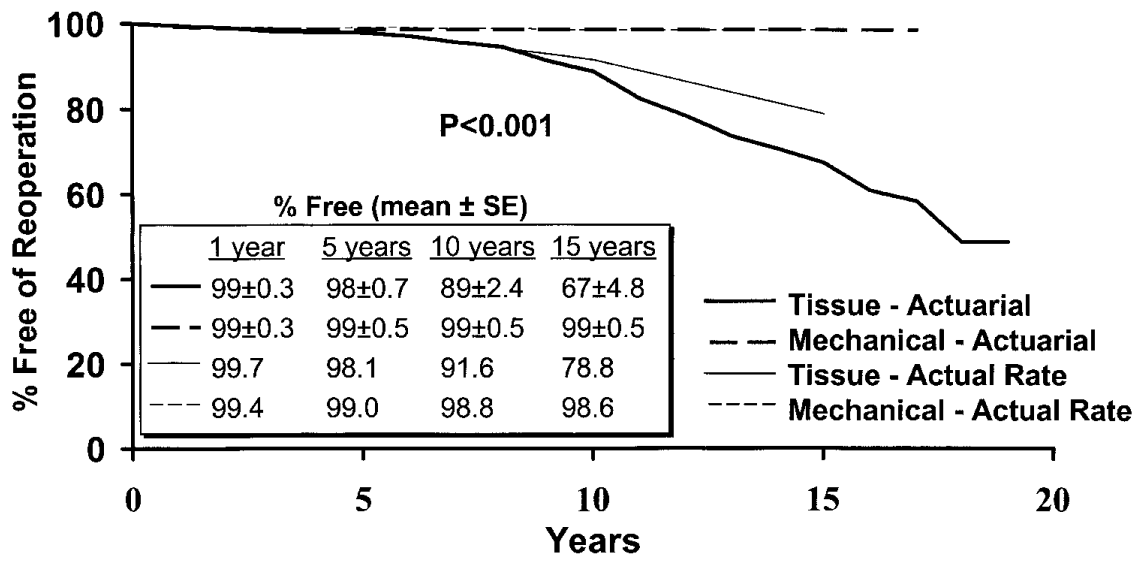

Number at Interval

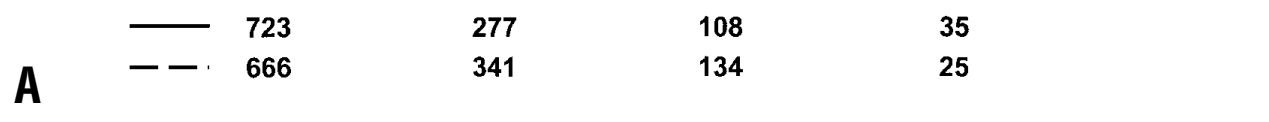

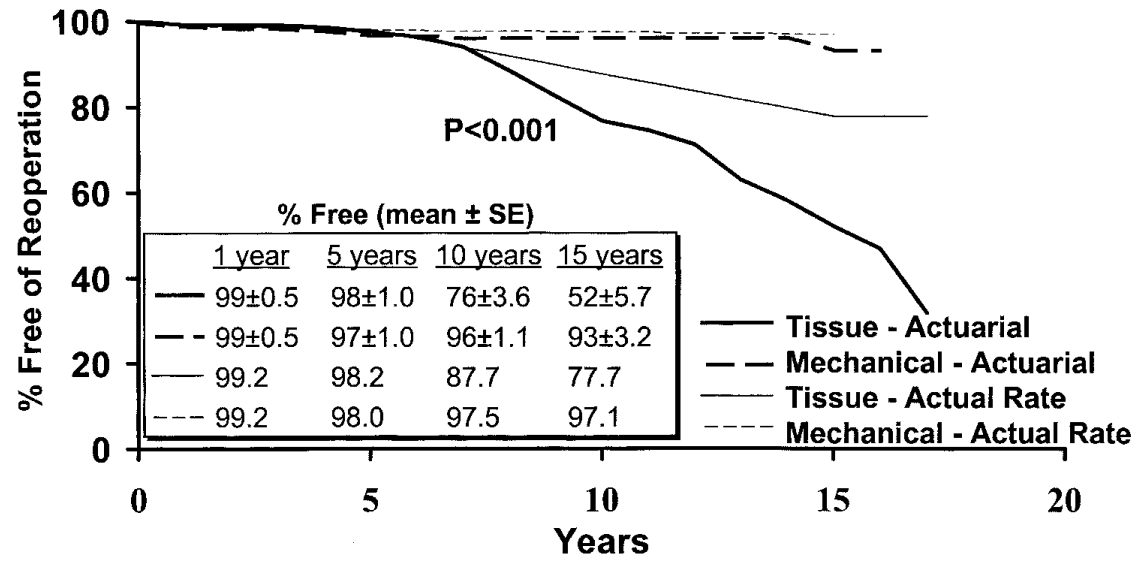

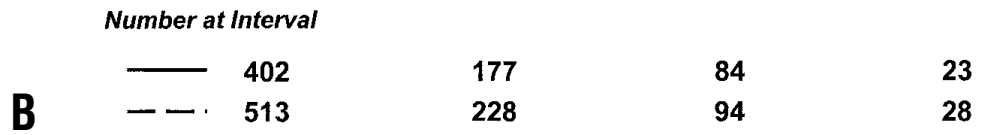

Figure 3. Actuarial and actual freedom from reoperation for tissue and mechanical valves categorized by age. The $\boldsymbol{P}$ values refer to the comparison of the actuarial tissue and mechanical data. A, Aortic tissue valve recipients; $B$, mitral tissue valve recipients.

In the comparison of valve complications, the survival curves for the tissue and mechanical valves cross over each other, complicating the analysis of statistical significance. Therefore, 2 tests of statistical significance are presented for these event rates, both calculated with BMDP 2L (BMDP Software, Los Angeles, Calif). ${ }^{7}$ The first, the Generalized Wilcoxon-Breslow (Breslow) statistic, weights early events to a greater extent and will therefore be more sensitive to early divergence of the valve event curves. The second test, the Generalized Savage (Mantel-Cox), is similar to the logrank test and weights early and late events equally.

\section{Results}

\section{Patient Characteristics}

Basic preoperative patient characteristics are presented in Table 1 stratified by valve type. Mechanical valve recipients were younger than tissue valve recipients $(P=.0001)$ and more often female. Patients receiving tissue and mechanical valves also differed in the cause of valve disease. Patients with papillary muscle infarction or ischemia were more likely to receive mechanical valves than porcine valves $(P=.0006)$. However, degenerative aortic valve disease was the most common cause for both tissue and mechanical aortic valve replacement.

Operative characteristics, including frequency of concurrent coronary bypass operations and operative mortality, are also summarized in Table 1. Minimal differences were seen in operative mortality between valve types $(9.8 \%$ for tissue valves vs $7.8 \%$ for mechanical valves, $P=.09$ ), but mortality did differ significantly by valve position (6.1\% for aortic valves vs $11.8 \%$ for mitral valves, $P=.001)$. 

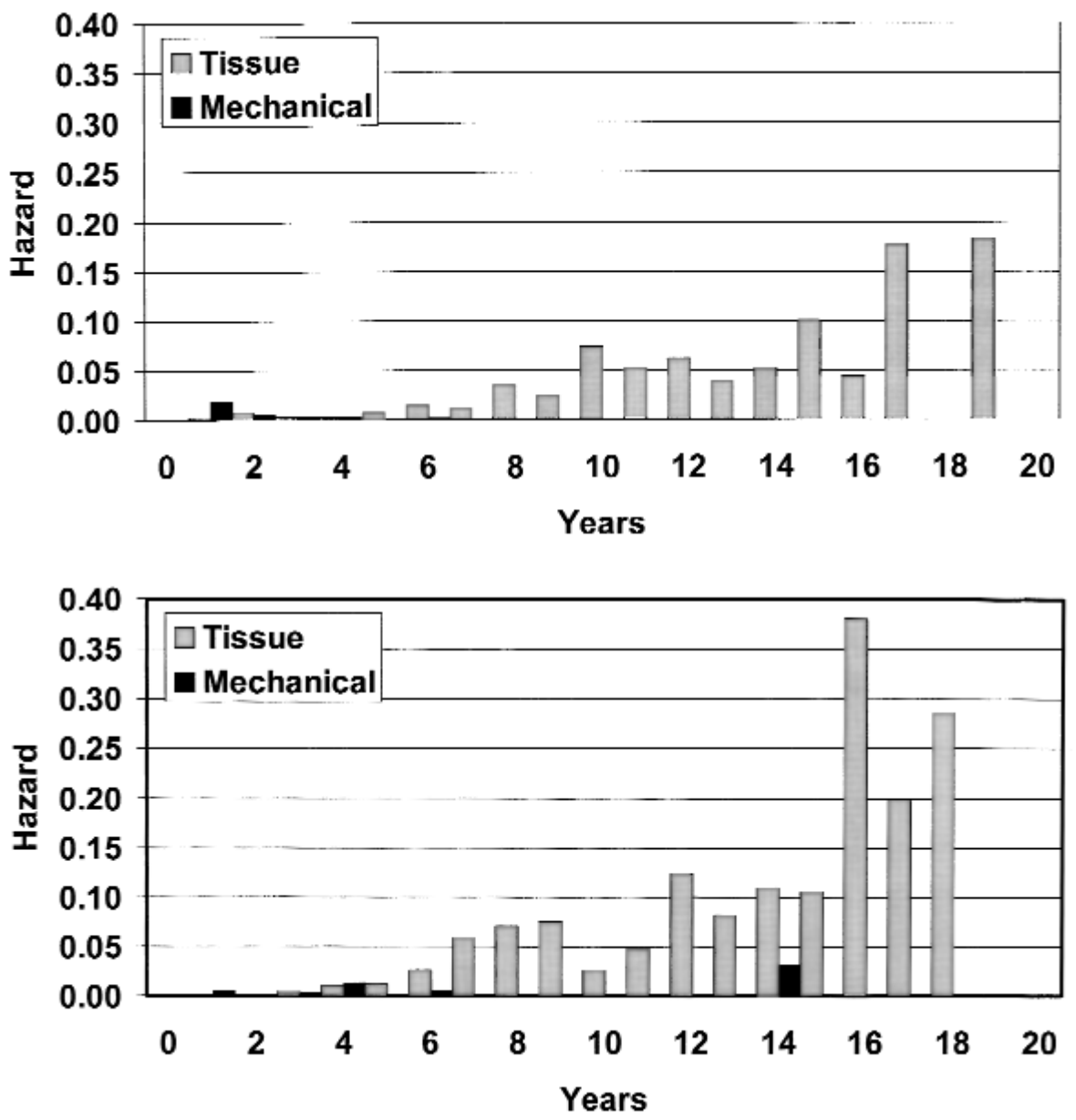

Figure 4. Annual risk (hazard) of undergoing valve reoperation. A, Aortic tissue valve recipients; $B$, mitral tissue valve recipients.

TABLE 3. Actual reoperation percentages

\begin{tabular}{ccc}
\hline & $\begin{array}{c}\text { Mechanical } \\
\text { (actual rate } \pm \text { SE) }\end{array}$ & $\begin{array}{c}\text { Tissue } \\
\text { (actual rate } \pm \text { SE) }\end{array}$ \\
\hline Aortic & & \\
$5 y$ & $0.99 \% \pm 0.44 \%(n=506)$ & $1.9 \% \pm 0.68 \%(n=412)$ \\
$10 y$ & $1.3 \% \pm 0.62 \%(n=319)$ & $8.4 \% \pm 1.8 \%(n=249)$ \\
$15 y$ & $1.4 \% \pm 0.97 \%(n=145)$ & $21.2 \% \pm 3.2 \%(n=165)$ \\
Mitral & & \\
$5 y$ & $2.0 \% \pm 0.71 \%(n=393)$ & $1.8 \% \pm 0.73 \%(n=334)$ \\
$10 y$ & $2.5 \% \pm 0.93 \%(n=280)$ & $12.3 \% \pm 2.0 \%(n=277)$ \\
$15 y$ & $2.94 \% \pm 1.45 \%(n=136)$ & $22.3 \% \pm 2.9 \%(n=211)$ \\
Aortic valve recipients $\geq 65 y$ & \\
$5 y$ & $1.2 \% \pm 0.59 \%(n=336)$ & $1.3 \% \pm 0.63 \%(n=313)$ \\
$10 y$ & $1.9 \% \pm 0.95 \%(n=209)$ & $5.8 \% \pm 1.9 \%(n=156)$ \\
$15 y$ & $2.1 \% \pm 1.5 \%(n=96)$ & $10.8 \% \pm 3.4 \%(n=83)$ \\
Mitral valve recipients $\geq 65 y$ & \\
$5 y$ & $1.4 \% \pm 0.84 \%(n=204)$ & $1.5 \% \pm 0.83 \%(n=206)$ \\
$10 y$ & $1.4 \% \pm 0.96 \%(n=147)$ & $7.6 \% \pm 2.1 \%(n=159)$ \\
$15 y$ & $1.4 \% \pm 1.4 \%(n=70)$ & $14.4 \% \pm 3.6 \%(n=97)$ \\
\hline
\end{tabular}

\section{Valve-Related Complications}

The 2 most common and most clinically significant long-term complications of valve replacement are embolic events and hemorrhage. There were no significant differences in embolic events for either the aortic or the mitral tissue and mechanical valve recipients (Figure 1, $A$ and $B$ ). At 15 years, between $71 \%$ and $75 \%$ of all patients were free of embolic events after tissue and mechanical valve replacement, respectively, regardless of valve position. The linearized rates of valve-related events are shown in Table 2 for aortic, mitral, and double valve recipients. The overall rate of in situ valve thrombosis was $0.21 \%$ per year for mechanical valves and $0.02 \%$ per year for tissue valves. The overall linearized embolism rate was $2.3 \%$ per year for all tissue valves and $2.8 \%$ per year for the St Jude Medical mechanical valves.

Major hemorrhage occurred less frequently than embolic events. The linearized hemorrhage rate for the patients receiving St Jude Medical valves was $2.1 \%$ compared with $1.1 \%$ for those receiving tissue valves. As shown in Figure 

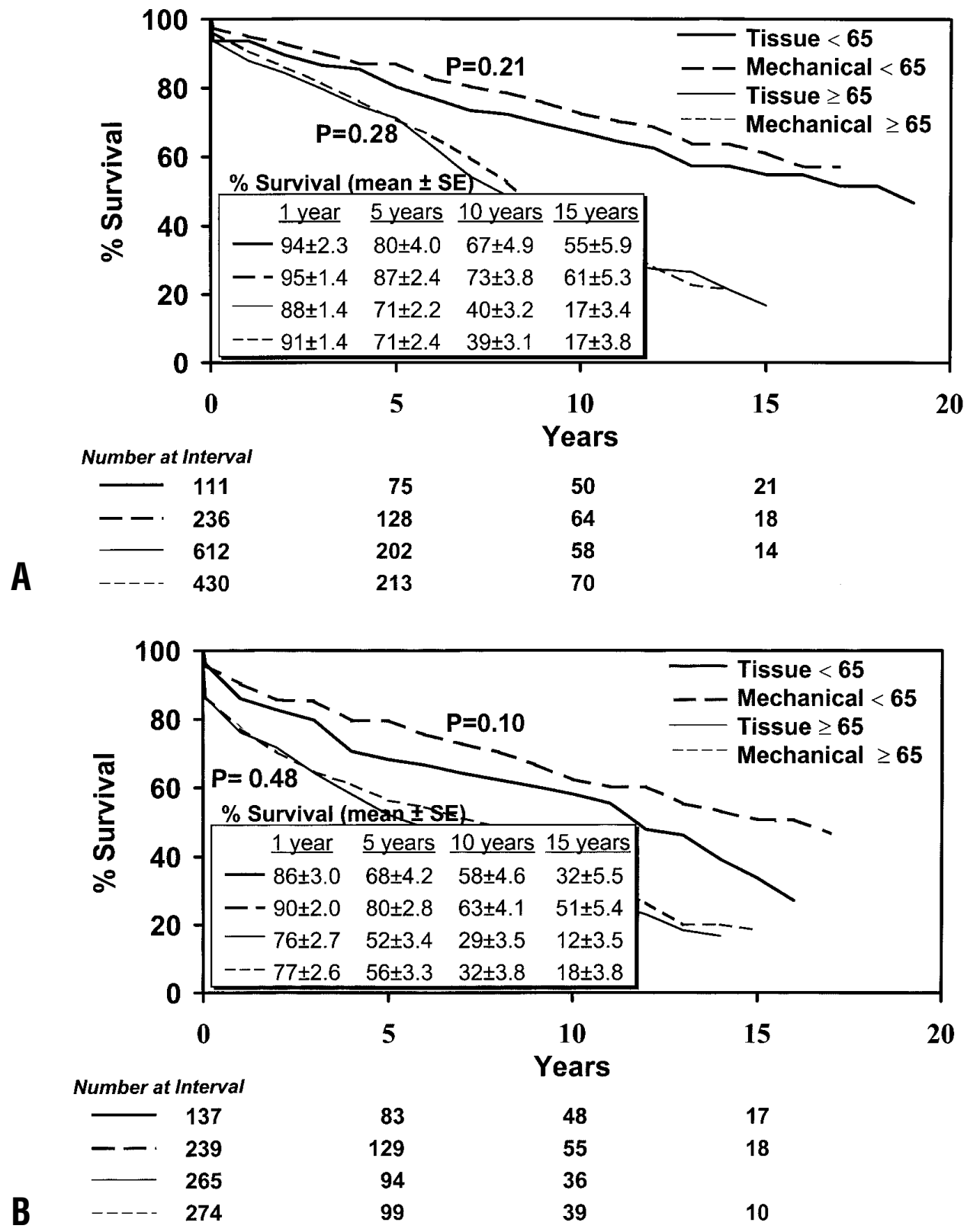

Figure 5. Survival stratified by patient age. A, Aortic tissue and St Jude Medical valve recipients; B, mitral tissue and St Jude Medical valve recipients. NS, Not significant.

2, $A$, hemorrhage was more common in aortic mechanical valve recipients $(P<.001)$. However, among the mitral valve recipients (Figure $2, B$ ) the frequency of hemorrhage was similar in those receiving tissue and mechanical valves. At 15 years, $86 \%$ and $85 \%$ of mitral tissue and mechanical valve recipients, respectively, were free of hemorrhage. Hemorrhage at 15 years was nearly identical in the mechanical aortic valve recipients, the mitral tissue valve recipients, and the mitral mechanical valve recipients (freedom from hemorrhage of $85 \%, 85 \%$, and $86 \%$, respectively).
Other valve complications were less common. No structural valve failure occurred in the St Jude Medical valve recipients (7463 patient-years of exposure). However, 107 of the tissue valve recipients had documented structural valve failure (5928 patient-years). Perivalvular leak occurred in 13 mechanical valve recipients and in 6 tissue valve recipients. Significant hemolysis occurred in 3 of the St Jude Medical valve recipients (linearized rate, $0.04 \%$ per year) but not in any of the tissue valve recipients. Endocarditis occurred in 61 patients overall, 24 receiving 
TABLE 4. Multivariable analysis of survival

\begin{tabular}{lll}
\hline & Hazard ratio & P value \\
\hline Aortic $(n=1114)$ & & \\
Age (decade) & $1.50(1.37-1.65)$ & $<.001$ \\
NYHA class IV & $1.65(1.40-2.03)$ & $<.001$ \\
Diabetes & $1.68(1.31-2.07)$ & $<.001$ \\
Mitral $(n=785)$ & & \\
Age (decade) & $1.40(1.26-1.56)$ & $<.001$ \\
NYHA class IV & $1.97(1.40-2.03)$ & $<.001$ \\
Diabetes & $1.41(1.09-1.81)$ & $<.01$ \\
Coronary disease & $1.58(1.28-1.97)$ & $<.001$ \\
\hline
\end{tabular}

Values are given as hazard ( $95 \%$ confidence intervals). NYHA, New York Heart Association.

${ }^{*}$ Age was analyzed as a continuous variable. The coefficient represents the increase in risk per additional decade of age.

mechanical valves and 37 receiving tissue mitral valves. Erosion (left ventricular rupture) occurred infrequently: 4 mechanical and 6 tissue valve recipients had erosion, all early after the operation and most in the setting of a recent acute myocardial infarction. ${ }^{8}$ Pannus formation (tissue ingrowth) was only reported in 2 mechanical valve recipients, with a linearized rate of $0.027 \%$ for mechanical valve recipients and $0 \%$ for tissue valve recipients.

\section{Reoperation}

As would be expected, actuarial reoperation rates were significantly higher for tissue valve recipients (Figure 3). Examination of these curves reveals similar freedom from reoperation for tissue and mechanical valves until approximately 7 years after the operation, when the curves rapidly begin to diverge. As Figure 4, $A$ and $B$, demonstrate, the annual risk (hazard) of undergoing reoperation increases progressively with time for the tissue valves. For both aortic and mitral tissue valves, the hazard is low until approximately 6 years and then rises at a progressively faster rate.

Trend analysis of the hazard function for tissue valve reoperation between 6 months and 19 years reveals a significant trend for the hazard to rise progressively over time (correlation of $0.91, P<.01$ ) for the combined aortic and mitral valve replacement data, indicating that the risk of reoperation does not level off but progressively increases the longer a patient has had a tissue valve implanted. As can be seen by comparing panels $A$ and $B$ of Figure 4 , there are 2 effects driving tissue valve reoperation: (1) a valve position effect in which mitral valve reoperation rates are about twice as high as those for aortic valves and (2) a progressively increasing risk of tissue valve failure with time that appears to be intrinsic to tissue valves.

Reoperation rates were also analyzed by using the actual or cumulative method. This technique provides an answer to the following question: What proportion of the patients will require reoperation before they die? The actual freedom from reoperation is graphed in Figure 3, $A$ and $B$, and also listed in Table 3. At 5, 10, and 15 years, $1.45 \%, 1.75 \%$, and $1.82 \%$ of mechanical valve recipients had actually undergone reoperation. However, in the tissue valve recipients, at 5,10 , and 15 years $1.89 \%, 10.5 \%$, and $21.4 \%$, respectively, had required reoperation. Thus, although at 5 years actual reoperation rates were similar, by 10 and 15 years there were clear differences in actual reoperation rates between tissue and mechanical valves.

\section{Survival Analysis}

Although survival was better for mechanical valve recipients overall $(P=.002)$ and for aortic $(P=.02)$ and mitral $(P=.03)$ valves when analyzed separately, tissue valve recipients were on average more than 7 years older. After grouping patients on the basis of age and valve position, mortality was similar for the tissue and mechanical valve recipients who received either an aortic or mitral valve (Figure 5, $A$ and $B$ ). However, the mitral mechanical valve recipients under the age of 65 years (Figure $5, B$ ) had a slightly better survival (borderline significance) than the tissue valve recipients (15-year survival, $51 \% \pm 5.3 \%$ vs $32 \% \pm 5.4 \%$, respectively; $P=.10$, Breslow; $P=.02$, Mantel-Cox). No differences were seen in the aortic valve recipients (Figure 5, A). Survival curves were also analyzed by stratifying patients with coronary artery disease. No significant differences in survival were seen between tissue and mechanical valves after stratifying by the presence or absence of coronary artery disease. Analysis of valve-related mortality (including deaths caused by hemorrhage and thromboembolism and deaths within 30 days of reoperation) revealed no differences in survival for either aortic or mitral valve recipients.

\section{Multivariable Survival Analysis}

A Cox multivariable analysis was performed to adjust for differences in the baseline patient characteristics between the tissue and mechanical valve groups. Variables considered for inclusion were those found to differ significantly between the tissue and mechanical valve recipients in the univariate analysis. These variables included patient age, sex, type of valve (tissue or mechanical), presence of coronary disease, and New York Heart Association class IV status. In addition, diabetes was included in the models, although it was not a significant univariate predictor. Initially, the aortic and mitral valve recipients were analyzed together along with terms testing for interactions between risk factors and valve position. This revealed significant interactions between the presence of coronary disease and valve position $(P=.03)$ and between age and valve position $(P<.001)$. Therefore, the Cox model analyses were then conducted separately for the aortic and mitral valve recipients, and the results are shown in Table 4. The final Cox model indicated that age, New York Heart Association class 


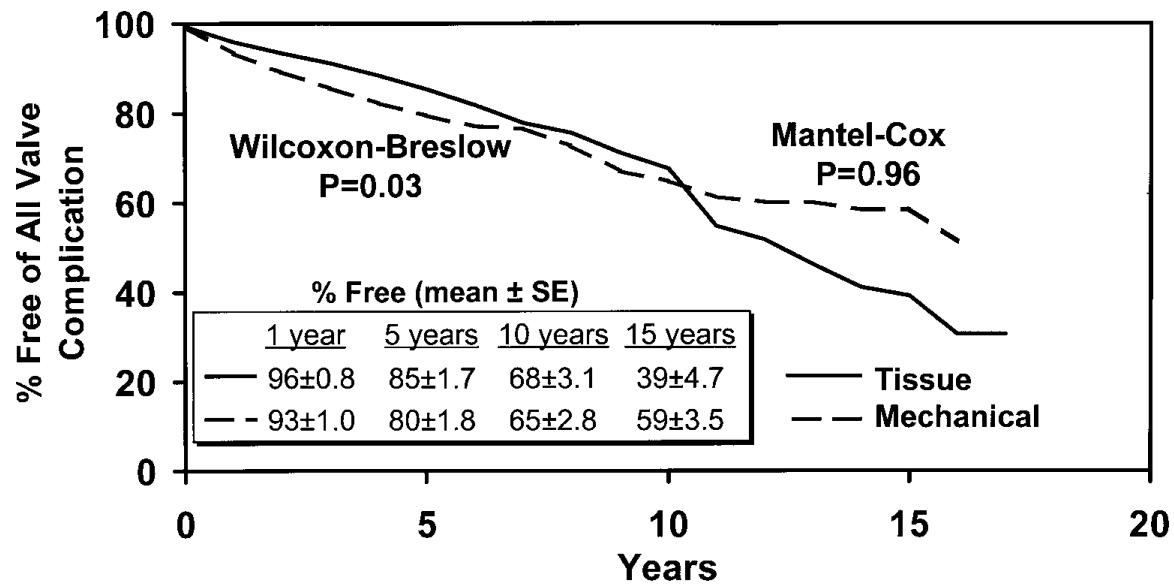

Number at Interval

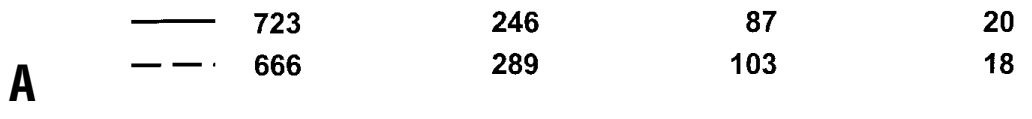

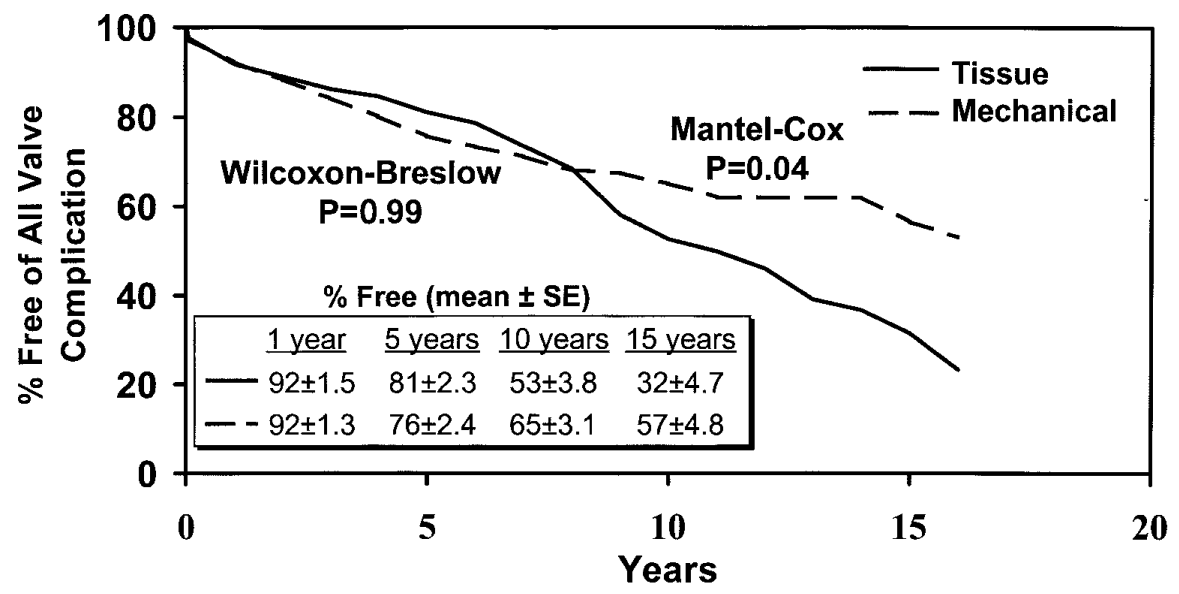
Number at Interval

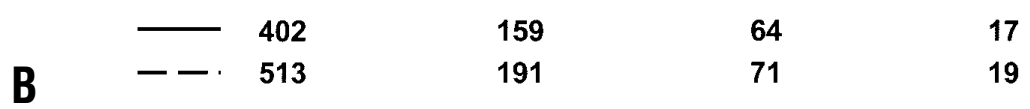

Figure 6. Freedom from all valve complications, including valve thrombosis, embolism, hemorrhage, perivalvular leak, structural failure, endocarditis, pannus formation, annular erosion, reoperation, valve-related death, death within 30 days of reoperation, valve failure, and hemolysis. A, Aortic valve recipients; $B$, mitral valve recipients. Two statistical tests are shown; the Wilcoxon-Breslow test gives greater weight to early events, and the MantelCox test weights early and late events equally. NS, Not significant.

IV status, and diabetes mellitus were significant predictors of survival for both the aortic and mitral valve recipients. Coronary disease was a significant predictor only for the mitral valve recipients. Importantly, tissue or mechanical valve type was not a significant predictor of survival in either the combined analysis or in the separate aortic or mitral analysis. The type of tissue valve implanted (porcine vs pericardial) and the type of porcine valve implanted
(Carpentier-Edwards porcine vs Hancock porcine) did not affect survival.

\section{Causes of Death}

A total of 1132 deaths occurred during follow-up, 564 in the mechanical valve recipients and 568 in the tissue valve recipients. In 128 patients the cause of death was missing or unclassified. Of 1004 patients with an identified cause of 
death, cardiac death accounted for 667 (66.4\%) and noncardiac death for 337 (33.6\%) patient deaths. Deaths that were judged to be valve related occurred in 174 patients (86 mechanical and 88 tissue), and sudden unexpected or unexplained death occurred in an additional 78 patients (40 mechanical and 38 tissue). Nonvalvular cardiac causes accounted for $45 \%$ (254/564) of mechanical valve-related deaths and $42 \%(239 / 568)$ of tissue valve-related deaths overall $(P=.35)$. Valve-related deaths accounted for only $15.2 \%(86 / 564)$ of mechanical valve-related deaths and $15.5 \%(88 / 568)$ of tissue valve-related deaths $(P=.97)$. The highest proportion of valve-related deaths were in the double valve recipients but still accounted for only $22 \%(17 / 77)$ of mechanical valve-related deaths and $26 \%$ (11/42) of tissue valve-related deaths in these patients $(P=.78)$.

\section{Overall Valve Complications}

The analysis of all valve complications is plotted in Figure 6, $A$ and $B$, and includes valve thrombosis, embolism, hemorrhage, perivalvular leak, structural failure, endocarditis, pannus formation, annular erosion, reoperation, valve-related death, death within 30 days of reoperation, valve failure, and hemolysis. Early valve complication rates were initially slightly higher for mechanical valves in both the aortic and mitral positions, although the differences were of borderline significance only for the aortic valves ( $P=.03$, Breslow). This early difference is probably the result of the higher hemorrhage rate seen in the mechanical aortic valve recipients.

However, the valve complication curves in Figure 6 demonstrate a crossover point for both the aortic and mitral valve recipients. For the mitral valve recipients, this crossover point occurs at approximately 7 to 8 years, and for the aortic valve recipients, it occurs at 10 years. Before this point, freedom from valve complications is better for tissue valve recipients than for mechanical valve recipients, whereas after the crossover point, freedom from complications is better for mechanical valve recipients. Statistical testing confirmed that late complication rates were significantly higher for the mitral tissue valve recipients $(P=.04$, Mantel Cox statistic). This crossover likely occurs as the rate of tissue valve reoperation accelerates and outweighs the constant ongoing risk of anticoagulant-related hemorrhage with mechanical valves.

\section{Discussion}

This study demonstrates similar outcomes in tissue and mechanical valve recipients over a 20 -year period. The small difference in survival of younger $(<65$ year of age) patients with mechanical mitral valves was of borderline significance and disappeared after adjustment for age. The risk of embolism did not differ between tissue and mechanical valves for either the aortic or mitral valve recipients. The primary difference in outcomes seen between these valve types was a higher risk of hemorrhage in the aortic mechanical valve recipients and a higher risk of structural failure in all tissue valve recipients. The crossover point in overall valve complications between tissue and mechanical valves is logical and follows from the progressively increasing rate of tissue valve reoperation balanced against a constant higher risk of hemorrhage in the mechanical valve recipients. The later crossover point of aortic valve recipients compared with that of mitral valve recipients is consistent with the higher rate of mitral valve recipient reoperation.

One of the most interesting observations in this study is the data set on the annual risk (hazard) of tissue valve reoperation. Analysis of the hazard (annualized rate) of tissue valve reoperation suggests that the risk of valve reoperation begins to rise in years 6 to 8 and increases progressively with time. No leveling off or reduction in risk of tissue valve failure was seen, and in fact, the plots of the hazard functions suggest a steady acceleration in the risk of tissue valve failure with time. These data provide a real-world estimate of the performance of these commonly implanted heart valves in a relatively elderly general population and demonstrate that the choice of a tissue or mechanical valve is primarily a balance of the risk of anticoagulation against the risk of reoperation.

Comparison of the linearized rates of hemorrhage and embolism for our St Jude Medical valve recipients with the literature demonstrates that our findings are consistent with series from the United States reported by Kratz, ${ }^{9}$ Fernandez, ${ }^{10}$ and their colleagues and with the hemorrhage rates reported by Ibrahim and coworkers ${ }^{11}$ from Ireland. However, our embolism rates are higher than those from Japan reported by Aoyagi, ${ }^{12}$ Nakano, ${ }^{13}$ and their associates and from Arom and coworkers ${ }^{14}$ in the United States and Baudet and colleagues ${ }^{15}$ in France. The higher rates of embolic events may be related to the greater age of our patients compared with those in these other series. For example, our overall mean patient age was $68 \pm 13$ years, whereas the mean patient ages in the series from Japan by Aoyagi and colleagues ${ }^{12}$ and Nakano and coworkers ${ }^{13}$ were 52 and 48 years, respectively. Our previous data suggest that the variation in thromboembolism rates in prosthetic valve recipients is strongly associated with nonvalvular patient risk factors for stroke, such as age and the presence of coronary disease. ${ }^{16}$

The embolism rates in our tissue valve recipient population are also somewhat higher than those observed by other authors, whereas our reoperation rates are lower. Fann and associates ${ }^{17}$ reported freedom from thromboembolism at 15 years of $87 \%$ for aortic valve recipients and $77 \%$ for mitral valve recipients compared with that in our series, in which $70 \%$ of aortic valve recipients and $73 \%$ of mitral valve recipients were free of embolism. However, the average patient ages in this series were 60 and 58 years for aortic 
and mitral valve recipients, respectively, compared with an average age for tissue valve recipients in our series of 72 years. As might be expected from this difference in patient age, freedom from reoperation was higher in our series. Thus, at 15 years, freedom from reoperation in the series of Fann and colleagues was $53 \%$ for aortic valve recipients and $33 \%$ for mitral valve recipients compared with $67 \%$ for aortic valve recipients and $52 \%$ for mitral valve recipients in our series. In a series by Jones and coworkers, ${ }^{18} 74 \%$ of aortic valve recipients and $61 \%$ of mitral valve recipients were free of reoperation for all causes at 10 years. Jamieson and colleagues, ${ }^{19}$ in a series of 1181 patients with CarpentierEdwards standard porcine valves, reported freedom from structural failure of $40.6 \%$ in aortic valve recipients and $8.5 \%$ in mitral valve recipients compared with our freedom from reoperation of $48.9 \%$ for aortic valve recipients and $26.0 \%$ for mitral valve recipients. These figures are not exactly comparable because we are reporting freedom from reoperation compared with freedom from structural failure and the population of Jamieson and coworkers is much younger (mean age of 57.9 years compared with our mean age of 68 years). In a somewhat older series of 1007 patients (all over 70 years; mean age, 75.6 years) receiving tissue valves, Pupello and colleagues ${ }^{20}$ reported a better freedom from structural failure: $80.4 \%$ at 15 years for aortic valve recipients and $84.6 \%$ for mitral valve recipients. Thus, our tissue valve reoperation rates fit between published series with younger and older patient populations.

The rates of other valve complications in our series are comparable with those reported by other authors. For example, the endocarditis rate was $0.3 \%$ per year for mechanical valve recipients in our series for both aortic and mitral valve recipients, which is similar to the $0.3 \%$ reported by NitterHauge and Abdelnoor ${ }^{21}$ in 1104 patients with the Medtronic Hall prosthesis and the $0.3 \%$ reported for all patients by Ibrahim and colleagues. ${ }^{11}$ The rate of valve thrombosis was $0.3 \%$ and $0.2 \%$ in our series for aortic and mitral valve recipients compared with $0.1 \%$ for aortic and mitral valve recipients in the series by Nitter-Hauge and Abdelnoor. ${ }^{21}$

\section{Limitations}

Although our conclusions regarding the relative limitations of mechanical and tissue valves agree with conventional thinking about the relative risks of hemorrhage and reoperation, several limitations must be kept in mind. First, our study was not a randomized comparison of tissue and $\mathrm{St}$ Jude Medical valves, and this creates the potential for bias in valve selection. Although we have tried to adjust for these differences in the survival analysis by using multivariable methods, there may be variables that were not adjusted for because they were not measured. However, the variables analyzed here completely explain any potential differences in survival, suggesting that other variables would not add to our understanding of survival differences. A second limitation is the use of standard porcine and pericardial valves. Other tissue valves, such as stentless valves and aortic homografts, or the Ross procedure may demonstrate different outcomes and event rates. We have also been unable to differentiate between major and minor thromboembolic events, which is an intrinsic limitation of our database. A final possible limitation is the combination of multiple types of tissue valves in the analysis: the Carpentier-Edwards porcine valve, the Hancock standard or modified orifice valves, and the Carpentier-Edwards pericardial valve. However, a recently published randomized trial with 1369 patient-years of follow-up demonstrated that there are no significant differences in durability between the Hancock and Carpentier-Edwards porcine valves. ${ }^{22}$ It remains less clear whether there are differences in event rates and durability between standard porcine valves and the CarpentierEdwards pericardial valve. However, it is important to point out that because the Carpentier-Edwards pericardial valve has only been used at our institution since 1992, the acceleration of the risk of valve reoperation at 7 to 10 years observed in the overall tissue valve group does not necessarily apply to this valve.

In summary, survival was similar after adjustment for risk factors with tissue and St Jude Medical mechanical valves in both aortic and mitral valve recipients. An increase in hemorrhage was seen in the aortic mechanical valve recipients, but embolism rates did not differ between valve types. Reoperation rates were significantly higher in all tissue valve recipients and appeared to accelerate after about 10 years. These data suggest that outcomes after tissue and mechanical valve replacement are similar, with the primary tradeoff being the risks of anticoagulant-related hemorrhage in mechanical aortic valve recipients versus the risk of reoperation after 8 to 10 years in tissue valve recipients.

We thank Dr Timothy Denton and Dr Richard Gray, without whose help this article would not have been possible.

\section{References}

1. Hammermeister KE, Henderson WG, Burchfiel CM, Sethi GK, Souchek J, Oprian C, et al. Comparison of outcome after valve replacement with a bioprosthesis versus a mechanical prosthesis: initial 5 year results of a randomized trial. J Am Coll Cardiol. 1987;10:719-32.

2. Bloomfield P, Kitchin AG, Wheatley DJ, Walbaum PR, Lutz W, Miller HC. A prospective evaluation of the Björk-Shiley, Hancock, and Carpentier-Edwards heart valve prostheses. Circulation. 1986;73: 1213-22.

3. Khan S, Gray R. Selection of a valve prosthesis in the elderly patient. In: Emery RW, Arom KV, editors. The aortic valve. Philadelphia: Hanley and Belfus; 1991. p. 149-160.

4. Edmunds LH, Clark RE, Cohn LH, Grunkemeier GL, Miller DC, Weisel RD. Guidelines for reporting morbidity and mortality after cardiac valvular operations. J Thorac Cardiovasc Surg. 1996;112:708-11.

5. Grunkemeier GL, Jamieson WRE, Miller DC, Starr A. Acutarial versus actual risk of porcine structural valve deterioration. $J$ Thorac Cardiovasc Surg. 1994;108:709-18. 
6. Khan S, Trento A, Kass R, DeRobertis M, Sandhu M, Nessim S. Actual failure rates: a method of assessing tissue valve reoperation rates. Am Heart J. 1999;139:108-13.

7. Dixon WJ, editor. BMDP 2L. BMDP statistical software manual, version 7.0. Berkeley (CA): University of California Press; 1992. p. 825-89.

8. Harold JG, Bateman TM, Czer LS, Chaux A, Matloff JM, Gray RJ. Mitral valve replacement early after myocardial infarction: attendant high risk of left ventricular rupture. J Am Coll Cardiol. 1987;9:277-82.

9. Kratz JM, Crawford FA Jr, Sade RM, Crumbley AJ, Stroud MR. St Jude prosthesis for aortic and mitral valve replacement: a ten-year experience. Ann Thorac Surg. 1993;56:462-8.

10. Fernandez J, Laub GW, Adkins MS, Anderson WA, Chen C, Bailey $\mathrm{BM}$, et al. Early and late-phase events after valve replacement with the St Jude Medical prosthesis in 1200 patients. J Thorac Cardiovasc Surg. 1994;107:394-406.

11. Ibrahim M, O'Kane H, Cleland J, Gladstone D, Sarsam M, Patterson C. The St Jude Medical prosthesis: a thirteen-year experience. $J$ Thorac Cardiovasc Surg. 1994;108:221-30.

12. Aoyagi S, Oryoji A, Nishi Y, Tanaka K, Kosuga K, Oishi K. Long-term results of valve replacement with the St Jude Medical valve. J Thorac Cardiovasc Surg. 1994;108:1021-9.

13. Nakano K, Koyanagi H, Hashimoto A, Kitamura M, Endo M, Nagashima M, et al. Twelve years' experience with the St Jude Medical valve prosthesis. Ann Thorac Surg. 1994;57:697-702.

14. Arom KV, Nicoloff DM, Kersten TE, Northrup WF, Lindsay WG, Emery RW. Ten years' experience with the St Jude Medical valve prosthesis. Ann Thorac Surg. 1989;47:831-7.

15. Baudet EM, Puel V, McBride JT, Grimaud JP, Roques F, Clerc F, et al. Long-term results of valve replacement with the St Jude Medical prosthesis. J Thorac Cardiovasc Surg. 1995;109:858-870.

16. Khan S, Czer L, Kass RM, et al. Age, coronary disease, and thromboembolism risk after St Jude mechanical valve replacement [abstract]. J Am Coll Cardiol. 1998;31(Suppl A):152A.

17. Fann JI, Miller DC, Moore KA, Mitchell RS, Oyer PE, Stinson EB, et al. Twenty-year clinical experience with porcine bioprostheses. Ann Thorac Surg. 1996;62:1301-11.

18. Jones EL, Weintraub WS, Craver JM, Guyton RA, Cohen CL, Corrigan VE, et al. Ten-year experience with the porcine bioprosthetic valve: interrelationship of valve survival and patient survival in 1,050 valve replacements. Ann Thorac Surg. 1990;49:370-83.

19. Jamieson WR, Burr LH, Munro AI, Miyagishima RT. CarpentierEdwards standard porcine bioprosthesis: a 21-year experience. Ann Thorac Surg. 1998;66(Suppl 6):S40-3.

20. Pupello DF, Bessone LN, Hiro SP, et al. Bioprosthetic valve longevity in the elderly: an 18-year longitudinal study. Ann Thorac Surg. 1995;60(Suppl 2):S270-4.

21. Nitter-Hauge S, Abdelnoor M. Ten-year experience with the Medtronic-Hall valvular prosthesis: a study of 1104 patients. Circulation. 1989;80(Suppl):I-43-8.

22. Sarris GE, Robbins RC, Miller DC, et al. Randomized, prospective assessment of bioprosthetic valve durability: Hancock versus Carpentier-Edwards valves. Circulation. 1993;88(Suppl):II-55-64.

\section{Discussion}

Dr W. R. Eric Jamieson (Vancouver, British Columbia, Canada). Dr Trento, this is a very important contribution because we now have to begin to identify the performance of biologic mechanical prostheses up to at least 15 years and maybe on to 20 years in our decision making with regard to what we offer and recommend to our patients. What you have really shown is that valve-related complications, reoperation, and survival are all very important points. Your summary slide does show that there is some preponderance of performance in aortic position with regard to less hemorrhage and with regard to putting in bioprostheses versus mechanical prostheses. In the mitral position there is not that major differentiation.

I have a number of questions for you, and the first concerns how you handled thromboembolism. You have not defined it. Is it all major events or both major and minor events, and did you include the events that occurred in the first 30 days?

Dr Trento. We included all events, both major and minor, including the first 30 days.

Dr Jamieson. Is there a difference between the major events that occurred with the mechanical prosthesis versus those occurring with the biologic prosthesis?

Dr Trento. We have not analyzed these differences. We had about 250 episodes of hemorrhage, but we did not analyze the major and minor hemorrhages.

Dr Jamieson. There is another point with relation to thromboembolism. In your article you note a number of thrombosis cases-I think 6 in the mechanical series and 4 in the tissue series. Could you elaborate on those? Were they aortic or mitral, and how were they managed?

Dr Trento. I do not remember whether they were aortic or mitral. Now we manage valve thrombosis by infusion of streptokinase, and that has been quite successful in our practice.

Dr Jamieson. I was interested because of the 6 cases in the mechanical series and the 4 cases in the biologic series. We have seen similar experience in the mechanical and mitral valves but not in the biologic valves.

You discussed a number of cases as annular erosion or left ventricular rupture. Were these early cases or late cases? Were they atrioventricular groove disruptions?

Dr Trento. The way they were classified is affected by the fact that this is a 20 -year data collection. Annular erosion and ventricular disruption are the same thing, the typical atrioventricular groove disruption.

Dr Jamieson. Did you see any cases in which the strut of the prosthesis eroded the ventricular wall? We saw this early in our experience if we inserted too large a mitral prosthesis, depending on the orientation.

Dr Trento. I think that all these events were early events. They were perioperative events.

Dr Jamieson. In your article you relate to the management of ischemic disease and muscle disruption, in which you implant a mechanical prosthesis in these patients. My concern is whether these patients have enough comorbidity to offer them a biologic prosthesis or whether these patients really do very well after muscle disruption in a mechanical prosthesis.

Dr Trento. This is obviously a process that may have changed over time in our practice. There have probably been about 15 surgeons over a period of 20 years performing these procedures. At the present time, it is the surgeon's decision as to what type of prosthesis to use in the presence of acute myocardial necrosis, and therefore we do not have a generalized and unified approach to this type of situation.

Dr Jamieson. Your article deals also with the concept of actual freedom versus actuarial freedom. A proponent of that is Dr Gary Grunkemeier, who is a member of our Association and who is here. One of the ways we are starting to look at our data is the actuarial freedom from mortality and reoperation but also permanent impairment or permanent morbidity to the patients. I know you did not analyze this. You did analyze it for reoperation but with regard to thromboembolism. Do you think that looking at the concept of actual freedom-which is really better information for our patients—would be more appropriate? 
Dr Trento. It is an interesting concept to look at the actual freedom from debilitating events and something that we should probably do. The concept of actual versus actuarial is a difficult concept to grasp. The actuarial concept looks at the valve and tells us how long the valve is going to last. The actual concept looks at the patient and tells us what the chance is for this patient to have a valve reoperation after 15 years. I think that expanding the actual concept to complication events other than reoperation may be very interesting.

Dr Jamieson. I have a question related to your reoperative mortality with regard to biologic prosthesis, specifically with regard to structural valve deterioration. Has that lessened over the years? Would you tend to place biologic prostheses in specific indications as a result?

Dr Trento. I do not think there was a statistical difference in operative mortality between reoperations and first-time reoperation. The operative mortality was slightly higher. We did 108 reoperations. I could not tell whether the incidence of mortality in the recent reoperations was much better.

Dr Jamieson. In our experience in the past 9 years, our mortality with reoperating on aortic or mitral valves is not different, and it was approximately $4 \%$.

It would be nice to see further age stratification of your data and maybe further actuarial analysis, but you did not indicate in your article whether this influenced your current practice. What is your recommended practice?

Dr Trento. I think that this article came out to be quite neutral, and we did not mean it in this way. We are open minded, and after reviewing the article, I think that each of you can probably arrive at different conclusions. I can only tell you my personal approach. Patients over age 65 years get a porcine aortic biologic prosthesis. Patients under age 60 years get either a mechanical prosthesis or some other type of procedure. For mitral valve recipients, patients over age 60 years with coronary artery disease probably get a biologic prosthesis, but that again is my preference. I think there are 8 surgeons in our group, and each of them has his own approach.

Dr Jamieson. Our current approach, according to a recent analysis of our data using the actuarial methodology, is that in the mitral position we place a bioprosthesis for patients over 70 years unless they have extensive comorbid disease. Patients under 70 years receive a mechanical prosthesis if the valve is not being repaired. In the aortic position, using actuarial methodology, our freedom from structural failure in patients over 70 years is $95 \%$ at 15 years, and in those patients between 61 and 70 years, the actuarial freedom is $88 \%$ at 15 years. Of course, below that you have the role of stentless prosthesis, autografts, and homografts.

\section{Bound volumes available to subscribers}

Bound volumes of The Journal of Thoracic and Cardiovascular Surgery are available to subscribers (only) for the 2001 issues from the Publisher, at a cost of $\$ 134.00$ for domestic, $\$ 165.85$ for Canadian, and $\$ 155.00$ for international subscribers for Vol 121 (January-June) and Vol 122 (July-December). Shipping charges are included. Each bound volume contains a subject and author index and all advertising is removed. Copies are shipped within 60 days after publication of the last issue of the volume. The binding is durable buckram with the Journal name, volume number, and year stamped in gold on the spine. Payment must accompany all orders. Contact Mosby, Subscription Customer Service, 6277 Sea Harbor Dr, Orlando, FL 32887, USA; phone 800-654-2452 or 407-345-4000.

Subscriptions must be in force to qualify. Bound volumes are not available in place of a regular Journal subscription. 